\title{
Dispersal capacity of the egg parasitoid Telenomus remus Nixon (Hymenoptera: Platygastridae) in maize and soybean crops
}

\author{
Aline Pomari-Fernandes ${ }^{\mathrm{a}}$, Adeney de Freitas Bueno ${ }^{\mathrm{b}, *}$, Sérgio Antonio De Bortoli ${ }^{\mathrm{c}}$, \\ Bruna Magda Favetti ${ }^{\mathrm{d}}$ \\ ${ }^{a}$ Universidade Federal da Fronteira Sul - UFFS, 85301-970 Laranjeiras do Sul, Paraná, Brazil \\ ${ }^{\mathrm{b}}$ Embrapa Soja, Laboratório de Parasitoides, 86001-970 Londrina, PR, Brazil \\ "Faculdade de Ciências Agrárias de Jaboticabal, Universidade Estadual Paulista "Júlio de Mesquita Filho" - UNESP, 14884-900 Jaboticabal, SP, Brazil \\ d Instituto Agronômico do Paraná - IAPAR, 86051-990 Londrina, Paraná, Brazil
}

\section{A R T I C L E I N F O}

\section{Keywords:}

Biological control

Augmentative releases

Spodoptera frugiperda

Zea mays

Glycine max

\begin{abstract}
A B S T R A C T
This study examined the dispersal capacity of the parasitoid Telenomus remus Nixon (Hymenoptera: Platygastridae) in soybean and maize crops. Knowledge on mobility and dispersal capacity of parasitoids is crucial for the implementation of successful biological control strategies using this biological control agent. Experiments were conducted at the experimental farm of Embrapa Soja located in Londrina, PR $\left(-51^{\circ} 11^{\prime} 0.54^{\prime \prime}\right.$ Long.; $-23^{\circ} 11^{\prime} 58.94^{\prime \prime}$ Lat.) in the crop seasons of 2012, 2012/13 and 2013 at different plant phenological stages. Experimental plots consisted of six concentric circles with radii of 5, 10, 15, 20, 25, and $30 \mathrm{~m}$, with 8, 24, 40, 56, 72 and 88 parasitoid traps per circle, respectively. Host eggs were placed on each plant as parasitoid traps. Approximately 150,000 newly emerged (up to $24 \mathrm{~h}$ old) adults of $T$. remus reared on eggs of Corcyra cephalonica Stainton (Lepidoptera: Pyralidae) or Spodoptera frugiperda (JE Smith) (Lepidoptera: Noctuidae) were released at the central point of each circle. Parasitism by T. remus decreased with increasing distance to the release points regardless of host, phenological stage, crop or season. Our findings allow the conclusion that $T$. remus should be released at a minimum density of 35 points/hectare in soybean crops and 34 points/hectare in maize crops to ensure T. remus dispersal over $100 \%$ of the area in the worst case scenario. Since wind direction influences the dispersal pattern of T. remus, the release methodology should be determined according to wind conditions, possibly with preference for a perimetric distribution of the released insects.
\end{abstract}

\section{Introduction}

Telenomus remus Nixon (Hymenoptera: Platygastridae) is an egg parasitoid introduced to Brazil for the control of Spodoptera frugiperda (J.E. Smith) (Lepidoptera: Noctuidae) (Pedrasi and Parra, 1986). This parasitoid has a high potential for use in augmentative biological control $(\mathrm{ABC})$ and stands out for being effective against various pest species of the genus Spodoptera Guenée (Lepidoptera: Noctuidae) (Pomari et al., 2012), mainly due to its high reproductive capacity (Cave, 2000; Bueno et al., 2008). However, the success of ABC depends on the ability of released parasitoids to disperse and locate adult food, shelter, and hosts (Paranhos et al., 2007). Since ABC targets an immediate effect by a mass release of natural enemies rather than by their establishment over a longer period of time, the insects must move reasonably fast from the release points and spread throughout the infested area (Corbett and Rosenheim, 1996). However, both extremely low or high dispersal rates involve potential disadvantages with respect to establishment, spread and efficacy of the released biological control agent (Heimpel and Asplen, 2011). Therefore, knowledge of mobility and dispersal capacity of parasitoids is crucial for the implementation of successful biological control strategies (Castillo et al., 2006).

Despite the importance of natural enemies for biological control, the number of studies on their dispersal capacity is limited, mainly because of the difficulties involved in measuring dispersal in small insects (Hougardy and Mills, 2006; Tabone et al., 2010). Moreover, the dispersal capacity of a parasitoid might vary related to species-specific or lineage-specific traits and the crop to which the natural enemy is released (Stinner et al., 1974; Lopes, 1988; Sá et al., 1993). Parasitoid dispersal capacity might also be affected by host mobility, e.g. the alateassisted dispersal of Aphelinus varipes (Foerster) (Hymenoptera:

\footnotetext{
* Corresponding author at: Rod. Carlos João Strass - Distrito de Warta, Caixa Postal 231, CEP 86001-970 Londrina, Paraná, Brazil.

E-mail addresses: aline.fernandes@uffs.edu.br (A. Pomari-Fernandes), adeney.bueno@embrapa.br (A. de Freitas Bueno), bortoli@fcav.unesp.br (S.A. De Bortoli), favettibruna@yahoo.com.br (B.M. Favetti).
} 
Table 1

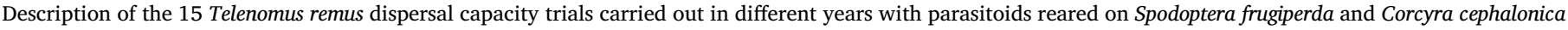
eggs together with the climate data recorded during the trials.

\begin{tabular}{|c|c|c|c|c|c|c|c|c|}
\hline & \multirow[t]{2}{*}{ Season } & \multirow[t]{2}{*}{ Trial } & \multirow[t]{2}{*}{ Plant phenological stages } & \multicolumn{3}{|c|}{ Temperature $\left({ }^{\circ} \mathrm{C}\right)$} & \multirow[t]{2}{*}{ Mean wind speed (knots) } & \multirow[t]{2}{*}{ Relative humidity (\%) } \\
\hline & & & & Max. & Min. & Mean & & \\
\hline \multirow[t]{9}{*}{ Maize } & \multirow[t]{3}{*}{2012 second season $^{1}$} & 1 & $\mathrm{~V} 2 / 3$ & 29.7 & 19.4 & 23.9 & 3.50 & 78.1 \\
\hline & & 2 & V5/6 & 25.3 & 17.0 & 20.7 & 4.28 & 80.6 \\
\hline & & 3 & V8/9 & 25.2 & 15.1 & 19.6 & 4.08 & 75.7 \\
\hline & \multirow[t]{3}{*}{$2012-13$ season $^{1}$} & 4 & V3 & 30.1 & 17.4 & 23.7 & 3.89 & 58.6 \\
\hline & & 5 & V6/7 & 26.0 & 18.7 & 22.1 & 6.22 & 82.3 \\
\hline & & 6 & V9/10 & 33.2 & 22.6 & 26.7 & 3.50 & 71.4 \\
\hline & \multirow[t]{3}{*}{2013 second season $^{2}$} & 7 & V2 & 25.6 & 17.3 & 21.2 & 4.28 & 86.3 \\
\hline & & 8 & V5 & 25.9 & 17.9 & 21.6 & 5.83 & 86.8 \\
\hline & & 9 & V10 & 26.1 & 15.4 & 20.7 & 3.69 & 71.2 \\
\hline \multirow[t]{6}{*}{ Soybean } & \multirow[t]{3}{*}{$2012-13$ season $^{1}$} & 10 & V7 & 28.7 & 21.3 & 24.2 & 4.28 & 83.7 \\
\hline & & 11 & R3 & 26.4 & 16.8 & 21.5 & 5.64 & 82.6 \\
\hline & & 12 & R6 & 27.9 & 20.1 & 23.0 & 3.50 & 88.8 \\
\hline & \multirow[t]{3}{*}{2013 second season ${ }^{2}$} & 13 & V3 & 26.4 & 16.6 & 21.0 & 4.86 & 77.2 \\
\hline & & 14 & $\mathrm{R} 1$ & 25.3 & 17.0 & 20.7 & 4.28 & 80.6 \\
\hline & & 15 & $\mathrm{R} 2 / 3$ & 24.1 & 10.5 & 17.9 & 3.69 & 56.6 \\
\hline
\end{tabular}

1 Trials carried out with two 2826- $\mathrm{m}^{2}$ infested plots with Telenomus remus reared on Spodoptera frugiperda eggs for 216 to 240 generations.

2 Trials carried out with one $2826-\mathrm{m}^{2}$ infested plot with Telenomus remus reared on Spodoptera frugiperda eggs for 216 to 240 generations and a second $2826-\mathrm{m}^{2}$ infested plot with Telenomus remus reared on Corcyra cephalonica eggs for nine generations.

Aphelinidae), a parasite of Aphis glycines Matsumura (Hemiptera: Aphididae). Despite of being parasitized, this aphid are able to fly what, therefore, will influence parasitoid dispersal (Heimpel and Asplen, 2011). Also, the conditions of each crop, such as the microclimate inside the canopy, can affect parasitoid dispersal capacity, mainly due to variation in temperature and leaf area for foraging (Biever, 1972). Thus, the aim of this study was to evaluate the dispersal ability of released $T$. remus adults and the spatial pattern of parasitism, using $S$. frugiperda eggs as traps in maize and soybean crops at different phenological development stages and climatic conditions.

\section{Material and methods}

\subsection{Experimental field}

Trials (Table 1) were carried out in the field $\left(23^{\circ} 12^{\prime} 28.6^{\prime \prime} \mathrm{S}\right.$ $51^{\circ} 10^{\prime} 56.5^{\prime \prime} \mathrm{W}$ ) in 2012 and 2013 in maize and soybean crops under integrated pest management at Embrapa Soja Station (Londrina county, Paraná state, Brazil). Because different growth stages in the same crop season were tested in the same locations, chlorpyrifos $384 \mathrm{~g}$ a.i.ha ${ }^{-1}$ was sprayed in the area following the experiment to avoid an influence of previously released parasitoids on the following trial. In addition, no chemical treatments had been applied for one week prior to the beginning of each trial. Each dispersal study was replicated three times. Then, trials $1,2,3,4,5,6,10,11$, and 12 were conducted in six $2826 \mathrm{~m}^{2}$ plots with the same climatic, agronomic and orographic features (three control plots and three treatment plots where the parasitoids were released), about $200 \mathrm{~m}$ from each other (Fig. 1A). Trials 7 , $8,9,13,14$, and 15 were conducted in nine $2826 \mathrm{~m}^{2}$ plots (Fig. 1B) in a randomized design testing parasitoids reared on eggs of Corcyra cephalonica (Stainton) (Lepidoptera: Pyralidae) and S. frugiperda.

The experiments with maize were carried out with the variety Balu $188^{\circledR}$ ( 5 plants per meter with a spacing of $0.70 \mathrm{~m}$ between rows). Soybean trials were carried out with BRS $295^{\circledR}$ cultivar (15 plants per meter with a spacing of $0.50 \mathrm{~m}$ between rows). Both are highly productive crop varieties in the state of Paraná, Brazil.

\subsection{Insect releases}

Telenomus remus adults used in the experiments as well as their hosts (eggs of $C$. cephalonica and S. frugiperda) were obtained from insect colonies kept at Embrapa Soja, Londrina, State of Paraná, Brazil under laboratory-controlled environmental conditions $\left[25 \pm 2{ }^{\circ} \mathrm{C}\right.$ temperature, $80 \pm 10 \%$ relative humidity, and $14 / 10 \mathrm{~h}$ photoperiod (L/D)].

Telenomus remus was originally collected in Ecuador and grown at the parasitoid rearing facilities of ESALQ/USP (Luiz de Queiroz College of Agriculture/University of São Paulo), from where some specimens were transferred to Embrapa Soybean 11 years ago (216 to 240 generations ago). In the laboratory, $T$. remus was reared using $S$. frugiperda egg masses (approximately 150 eggs each), which were glued onto a cardboard sheet $(2 \mathrm{~cm} \times 8 \mathrm{~cm})$. This carboard sheet was put together (in the same tube) with eggs previously parasitized by $T$. remus close to adult emergence. Small drops of honey were placed inside these tubes to feed the adults as soon as they emerged. The tubes were then closed, and eggs were allowed to be parasitized for $24 \mathrm{~h}$. Adults emerging from these eggs were used for trials or colony maintenance.

Spodoptera frugiperda was originally collected from maize plants in Rio Verde, State of Goiás, and had been kept in the laboratory for approximately nine years, fed on the artificial diet described by Greene et al. (1976) and Parra (2001). New field insects were introduced on a yearly basis to maintain insect quality. Perkins (1979) reported successful rearing of $S$. frugiperda in the laboratory for more than 18 years without any indication of degeneration.

Corcyra cephalonica was collected from UNESP/Jaboticabal and had been kept in the laboratory for approximately three years. This species was reared on its natural diet, using a methodology adapted from rearing Anagasta kuehniella (Zeller) (Lepidoptera: Pyralidae) (Parra, 1997).

In each of the treated plots, 150,000 newly emerged (up to $24 \mathrm{~h}$ old) adults of $T$. remus were released in the first hours of the morning at the central points of each circular plot (for a detailed description of plots see next section "Sampling"), while the other plots were used as untreated controls (Fig. 1). The number of released T. remus was based on recommendations by Pomari et al. (2013). Adults (up to $24 \mathrm{~h}$ after emergence) were fed with honey and distributed into plastic pots $(2 \mathrm{~L})$ covered with PVC plastic film. The pot was kept in the soil in the center of the circles (Fig. 1). At the time of release, the PVC plastic film was removed to allow the parasitoids to exit.

\subsection{Sampling}

Each plot was made up of six concentric circles with radii of 5,10 , $15,20,25$, and $30 \mathrm{~m}$ with $8,24,40,56,72$ and 88 parasitoid traps per circle, respectively (Fig. 1). Each parasitoid trap was composed by a 


\section{A}

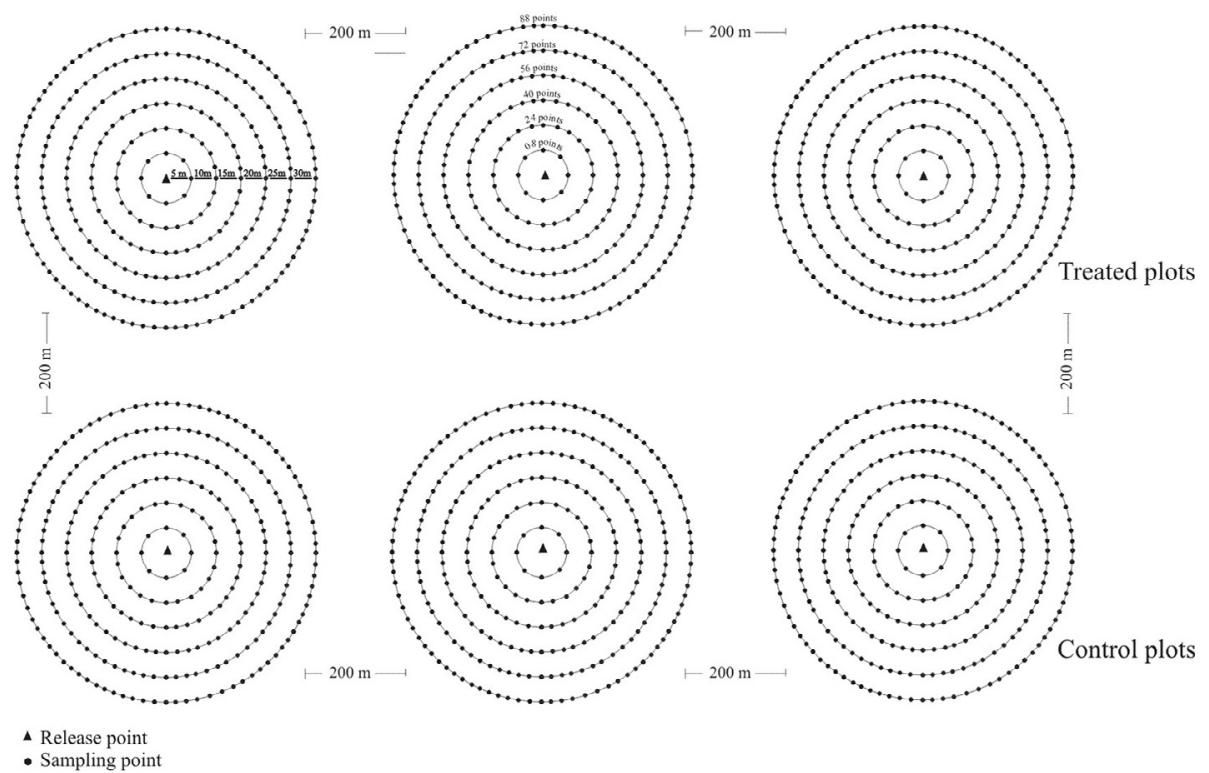

\section{B}

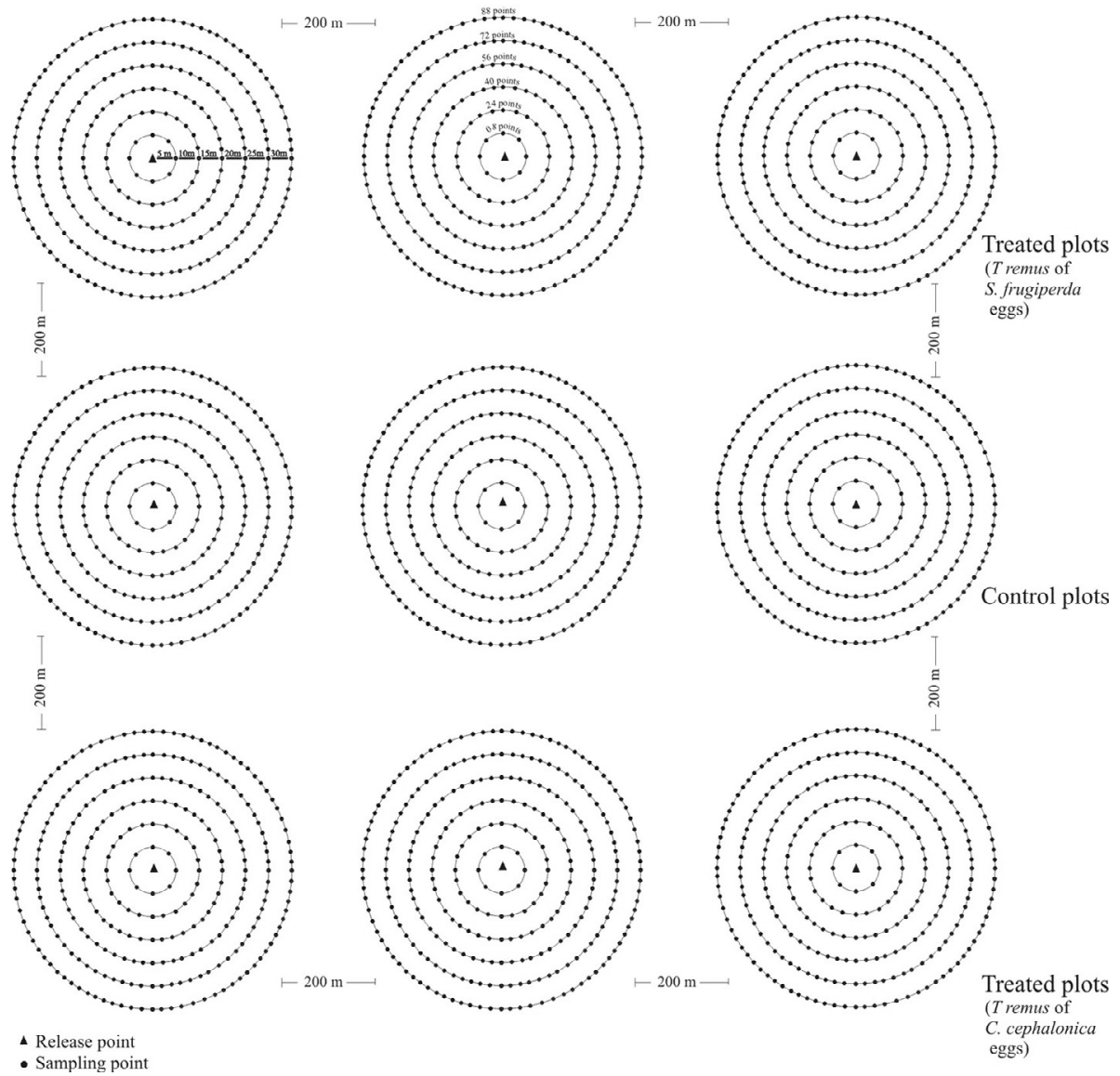

Fig. 1. Schematic illustration of the experimental setup for the dispersal of Telenomus remus in the field.

plant which was infested with a Spodoptera frugiperda egg mass of approximately 100 eggs according to the methodology proposed by Sá et al. (1993) and Bueno et al. (2012) for the egg parasitoid
Trichogramma pretiosum Riley (Hymenoptera: Trichogrammatidae). This experimental setup was identical for maize and soybean. In maize plants, $S$. frugiperda egg masses used as traps for T. remus were stapled 
to the abaxial part of leaves and near the pods. In soybean plants, eggs were stapled to the abaxial part of the leaves and to the upper part of the plants (mimicking oviposition patterns of the moth in both crop species).

Spodoptera frugiperda eggs were exposed to parasitism for $24 \mathrm{~h}$, after which they were removed and replaced by new eggs. This procedure was repeated 48, 72 and $96 \mathrm{~h}$ after parasitoid release (4 days). Daily, eggs were collected, placed in petri dishes, and maintained in an environmentally controlled incubator $\left[25 \pm 2{ }^{\circ} \mathrm{C}\right.$ temperature, $80 \pm 10 \%$ relative humidity, and $14 / 10 \mathrm{~h}$ photoperiod (L/D)] until adult parasitoids emerged.

\subsection{Data analysis}

The mean distance of dispersal (MD) and the area of dispersal of the parasitoid $\left(\mathrm{s}^{2}\right)$ in maize and soybean crops were determined using the average of the 4 sampling days (24, 48, 72 and $96 \mathrm{~h}$ after parasitoid release) as input to the model proposed by Dobzhansky and Wright (1943), according to the equations:

$s^{2}=\sum\left(r^{3} * i / a\right) /\left[\sum(r * i / a)+C / 2 \pi\right]$

$\left.D M=\sum\left(r^{2} * i / a\right) /\left[\sum(r * i / a)+C / 2 \pi\right)\right]$

where:

$\mathrm{s}^{2}=$ variance, indicating the area of dispersal $\left(\mathrm{m}^{2}\right)$;

$\mathrm{MD}=$ mean dispersal distance $(\mathrm{m})$;

$\mathrm{r}=$ distance from the center to the traps;

$a=$ number of traps per circle;

$C=$ mean number of parasitized eggs per trap, in the central circles

(circles of 15 and $20 \mathrm{~m}$ ); and

$\mathrm{i}=$ total parasitized eggs in each circle.

The number of release points ensuring adequate dispersal of the parasitoid was determined by dividing the release area by dispersal area $\left(\mathrm{s}^{2}\right)$. In addition, a regression analysis was performed to establish the mathematical relationship between dispersal radius and parasitism. Also, at trials $7,8,9,13,14$ and $15 t$ test $(p \leq 0.05)$ was used to compare parasitoids reared on $C$. cephalonica with parasitoids reared on $S$. frugiperda eggs in a randomized design (SAS Institute, 2009).

The influence of wind speed and direction was evaluated using the Beaufort Scale (Silveira Neto et al., 1976; Beer, 2013). Graphs showing parasitoid dispersion in relation to these factors were made with SigmaPlot software V.12.0 (Systat Software, 2010).

\section{Results}

Parasitism of $T$. remus on $S$. frugiperda eggs decreased linearly with increasing distance from the parasitoid release point regardless of crop species (results for maize in Fig. 2A, and for soybean in Fig. 2B) or host species ( $S$. frugiperda or $C$. cephalonica). These results were similar for all studied plant development stages and seasons (Fig. 2). In the second crop season of 2012, T. remus parasitism on $S$. frugiperda eggs was lower at the initial growth stage of maize (V2/V3 plant growth stage) than at later developmental stages (V5/V6 and V8/V9 plant growth stage) (Fig. 2A). In contrast, in the following crop seasons, lower parasitism at early plant development stages was observed neither for maize (Fig. 2A) nor for soybean (Fig. 2B).

With regard to weather conditions, temperature was stable during the experiments (Table 1). As expected, temperature was higher during the summer crop season (crop season 2012-2013) than during the second crop seasons (fall/winter of 2012 and 2013) but mean temperature only ranged from a minimum of $17.9^{\circ} \mathrm{C}$ (trial 15 - fall/winter crop season of 2013) to a maximum of $24.2^{\circ} \mathrm{C}$ (trial 10 - summer crop season of 2012/2013) (Table 1). Similarly, there was also no great variation in the values for relative humidity and wind condition (Table 1). Relative humidity ranged from a minimum of $58.6 \%$ (trial 4) to a maximum of $88.8 \%$ (trial 9) (Table 1). Wind ranged from a minimum of 3.5 knots (trials 1, 6 and 12) to a maximum of 6.22 knots (trial 5) (Table 1). The observed wind was classified between forces 1 and 3 according to the Beaufort Wind Scale (Silveira Neto et al., 1976; Beer, 2013).

Wind direction had an effect on parasitoid dispersal capacity (Figs. 3-6). Telenomus remus dispersal capacity was directly related to wind direction, regardless of crop [maize (Figs. 3 and 4) or soybean (Figs. 5 and 6)], or host (Figs. 4 and 6). Dispersal of T. remus was only homogenous when released on maize (2012 second season) at development stage V8/V9 (Fig. 3C). In all other trials, parasitoid dispersal was related to wind direction (Figs. 3-6).

Based on the model of Dobzhansky and Wright (1943), the area of dispersal $\left(s^{2}\right)$ and mean dispersal distance (MD) were similar between crops and parasitoids reared on different hosts (Table 2). Differences were noted only between parasitoids reared on $S$. frugiperda and $C$. cephalonica eggs on trials 9, 14 and 15 (Table 2). In trial 9 (maize 2013 second season) the area of dispersal $\left(\mathrm{s}^{2}\right)$ was greater for parasitoids reared on $S$. frugiperda eggs $\left(408.61 \pm 23.59 \mathrm{~m}^{2}\right)$ than parasitoids reared on $C$. cephalonica eggs $\left(298.73 \pm 18.97 \mathrm{~m}^{2}\right)$ (Table 2; $\left.p=0.0222 ; \mathrm{F}=13.17 ; \mathrm{df}_{\text {residue }}=4\right)$. In contrast, area of dispersal $\left(\mathrm{s}^{2}\right)$ and mean dispersal distance (MD) were greater of parasitoids reared on C. cephalonica eggs than parasitoids reared on $S$. frugiperda eggs in trials 14 (Table 2; $p=0.0232 ; \mathrm{F}=12.80 ; \mathrm{df}_{\text {residue }}=4$ and $p=0.0089$; $\mathrm{F}=22.64 ; \mathrm{df}_{\text {residue }}=4$, for $\mathrm{s}^{2}$ and $\mathrm{MD}$, respectively) and 15 (Table 2; $p=0.0299 ; \quad \mathrm{F}=10.90 ; \quad \mathrm{df}_{\text {residue }}=4$ and $p=0.0204 ; \quad \mathrm{F}=13.89 ;$ $\mathrm{df}_{\text {residue }}=4$, for $\mathrm{s}^{2}$ and $\mathrm{MD}$, respectively).

Telenomus remus from $S$. frugiperda eggs had a mean dispersal distance (MD) in maize ranging from a minimum of $17.47 \mathrm{~m}$ (trial 5, maize, growth stage V6/7 in the season of 2012/13) to a maximum of $20.31 \mathrm{~m}$ (trial 4, maize, growth stage V3 in the second season of 2012) (Table 2). The area of dispersal $\left(\mathrm{s}^{2}\right)$ varied from a minimum of $354.83 \mathrm{~m}^{2}$ (trial 5) to a maximum of $462.80 \mathrm{~m}^{2}$ (trial 4) (Table 2). By dividing the release area by dispersal area $\left(s^{2}\right)$, it follows that the number of release points to ensure adequate dispersal of the parasitoid is 21 points in the best case scenario and 29 points in the worst case scenario to ensure T. remus from $S$. frugiperda eggs dispersal in a $100 \%$ of maize crop (Table 2).

The dispersal capacity in maize of $T$. remus reared on $C$. cephalonica eggs was similar or eventually lower compared with parasitoids reared on $S$. frugiperda eggs (Table 2). The dispersal mean distance (MD) of parasitoids reared on $C$. cephalonica eggs ranged from a minimum of $15.56 \mathrm{~m}$ (trial 9, maize, growth stage V10 in the second season of 2013) to a maximum of $19.05 \mathrm{~m}$ (trial 8, maize, growth stage V5 in the second season of 2013) (Table 2). The area of dispersal $\left(s^{2}\right)$ varied from $298.73 \mathrm{~m}^{2}$ (trial 9) to $451.37 \mathrm{~m}^{2}$ (trial 8). Thus, the number of release points to ensure adequate dispersal of the parasitoid from $S$. frugiperda eggs varied from 23 to 34 points to ensure $100 \%$ T. remus dispersal in maize (Table 2).

In soybean, the dispersal capacity of $T$. remus reared on $S$. frugiperda eggs ranged from a minimum of $14.95 \mathrm{~m}$ (trial 12, soybean, growth stage R6, season $2012 / 2013$ ) to a maximum of $20.50 \mathrm{~m}$ (trial 10, soybean, growth stage V7, season 2012/2013) (Table 2). The area of dispersal $\left(\mathrm{s}^{2}\right)$ ranged from $298.37 \mathrm{~m}^{2}$ (trial 13, soybean, growth stage V3, second season 2013) to $494.35 \mathrm{~m}^{2}$ (trial 10) (Table 2). Therefore, the required number of releasing points ranges from 20 to 34 points.

The dispersal capacity (MD) and area of dispersal $\left(\mathrm{s}^{2}\right)$ of $T$. remus reared on C. cephalonica eggs in soybean ranged from $14.49 \mathrm{~m}$ and $287.90 \mathrm{~m}^{2}$ (trial 13, soybean, growth stage V3, second season of 2013) to $22.34 \mathrm{~m}$ and $561.61 \mathrm{~m}^{2}$, respectively (trial 14, soybean growth stage R1, second season of 2013) (Table 2). Therefore, from 18 to 35 release points are required to ensure $100 \% \mathrm{~T}$. remus dispersal in soybean in best and worst case scenario, respectively (Table 2). 


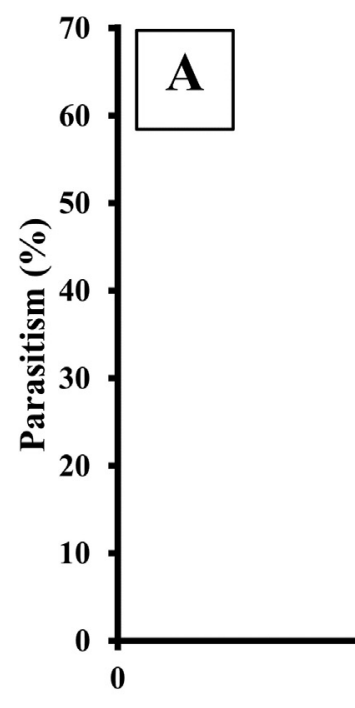

$\Delta$

$\diamond$

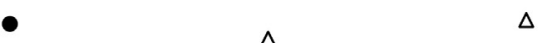

$\triangle$

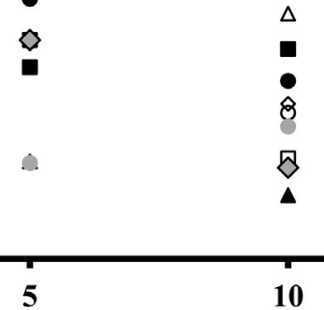

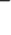

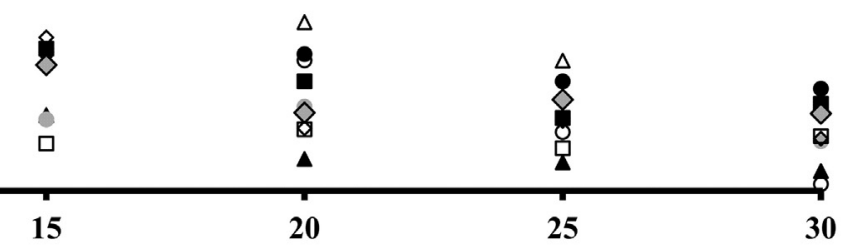

Distance (m)

$\triangle V 2 / 3(2012)^{*} ; y=-0.3507 x+12.158 ; R^{2}=0.8682$

$\triangle V 8 / 9(2012) * y=-1.4607 x+67.792 ; R^{2}=0.9754$

$\circ V 6 / 7(2012 / 13)^{*} ; y=-0.8687 x+28.511 ; R^{2}=0.9227$

$\square \mathrm{V2}(2013) * * ; y=-\mathbf{0 . 6 3 0 2 x}+\mathbf{2 6 . 5 0 5} ; \mathrm{R}^{2}=0.8518$

$V 10(2013) * * ; y=-0.6302 x+26.505 ; R^{2}=0.8518$

$\diamond V 5(2013)^{*} ; y=-1.1268 x+35.353 ; R^{2}=0.7824$
$\Delta V 5 / 6(2012) * ; y=-1.5836 x+53.817 ; R^{2}=0.8463$

- V3(2012/13)*; $y=-0.6529 x+29.097 ; R^{2}=0.8455$

V9/10(2012/13)*; $y=-0.2578 x+14.142 ; R^{2}=0.5678$

$\square V 5(2013) * * ; y=-0.6395 x+21.192 ; R^{2}=0.6014$

-V2(2013)*; $y=-0.4938 x+21.632 ; R^{2}=0.5516$

$V 10(2013) * ; y=-0.4938 x+21.632 ; R^{2}=0.5516$

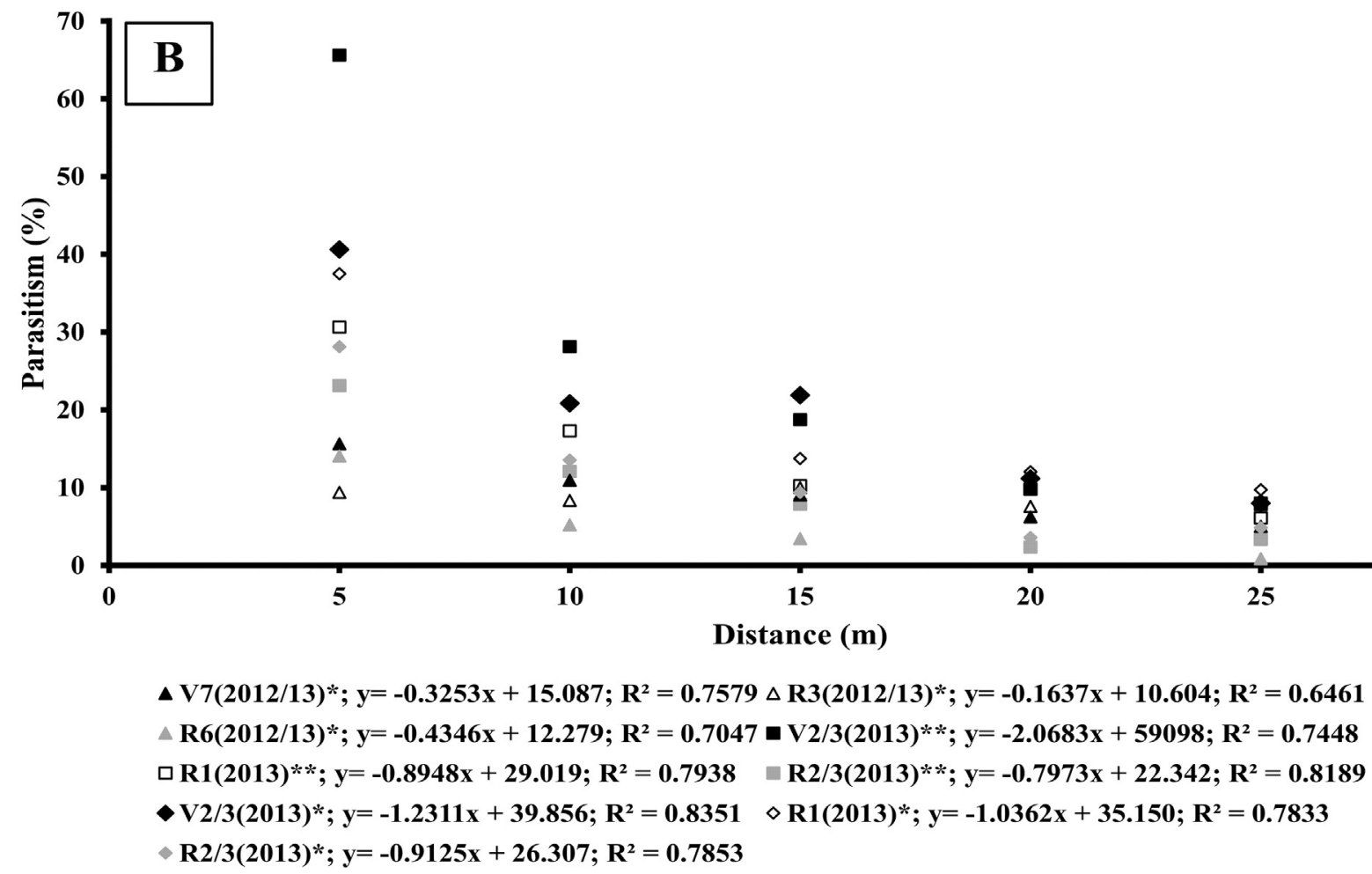

Fig. 2. Parasitism of Telenomus remus on Spodoptera frugiperda eggs after parasitoid release in maize (A) and soybean (B) at different plant phenological stages in the second season of 2012, the 2012/13 crop season and the second season of 2013. Londrina, Paraná State, Brazil. "Release performed with parasitoids reared on $S$. frugiperda eggs. ${ }^{* * *}$ Release performed with parasitoids reared on C. cephalonica eggs. 


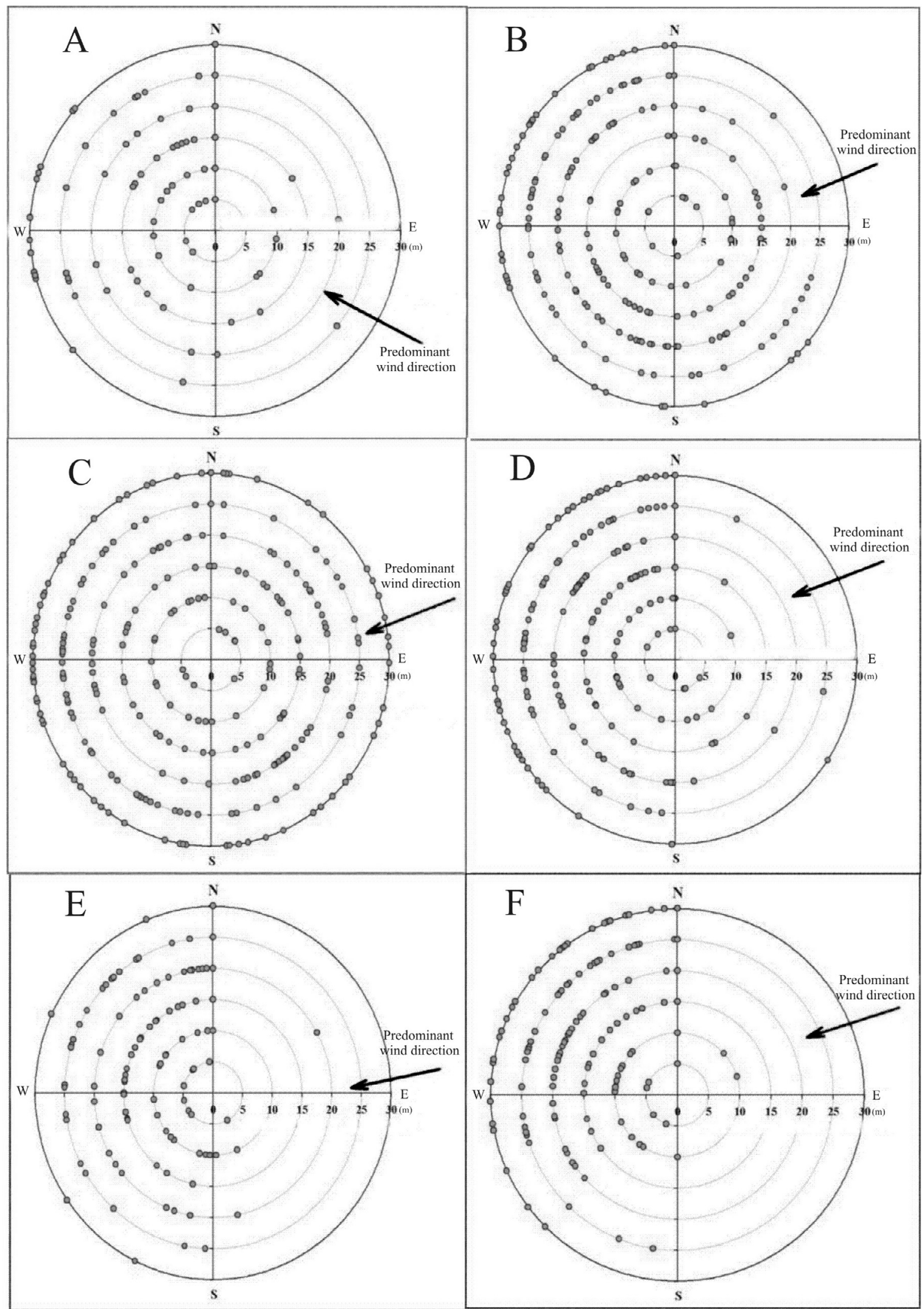

Fig. 3. The effect of wind direction on the dispersal of Telenomus remus. Each point represents a parasitized egg mass of Spodoptera frugiperda in various phenological stages of maize. A) V2/3, B) V5/6 and C) V8/9 (2012 second season) D) V3, E) V6/7 and F) V9/10 (2012/13 season). Londrina, PR, Brazil. 


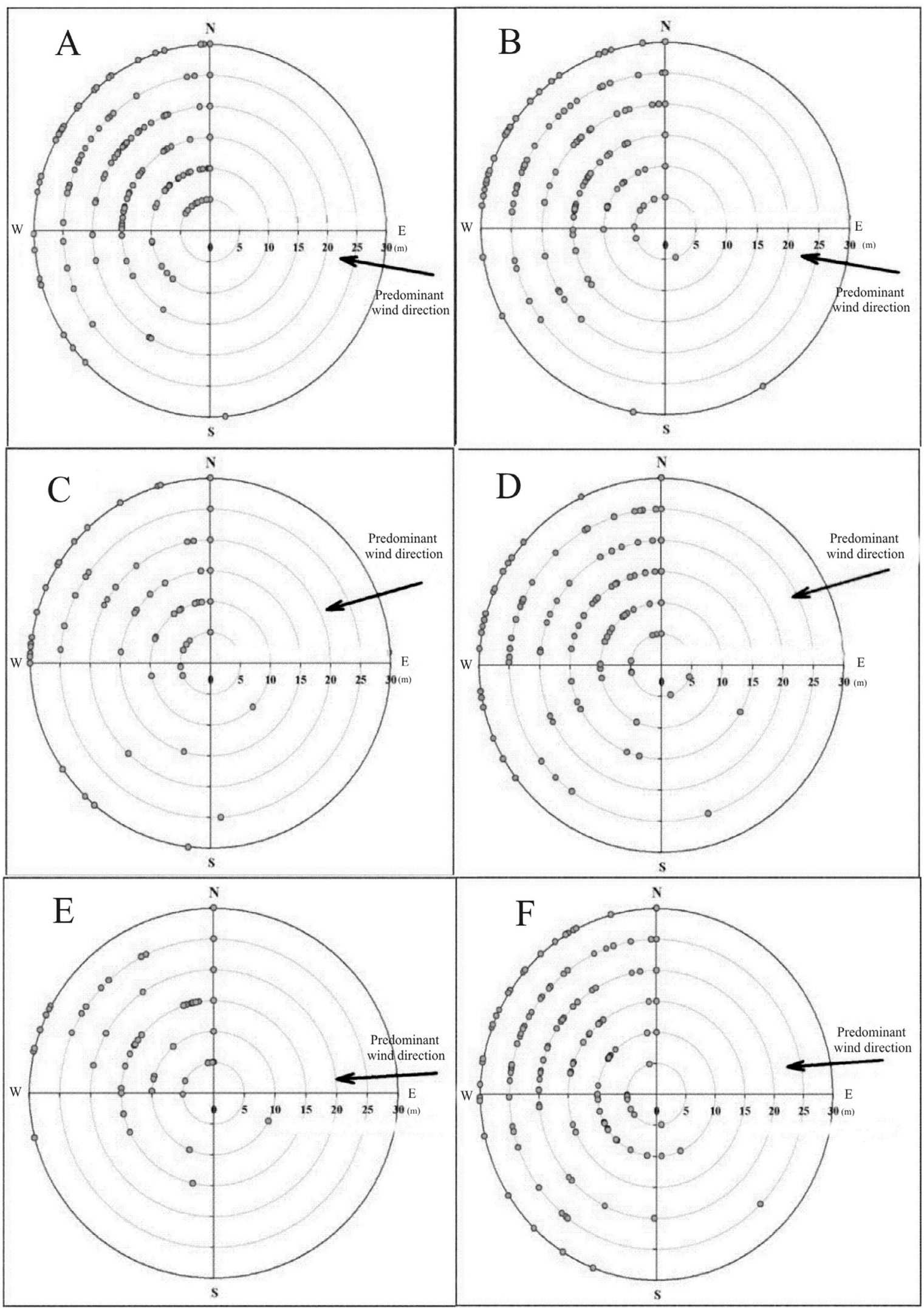

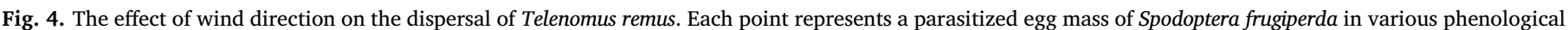

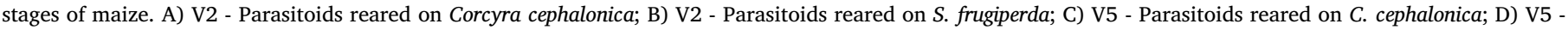

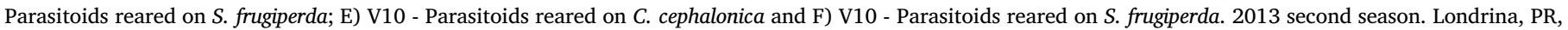
Brazil. 


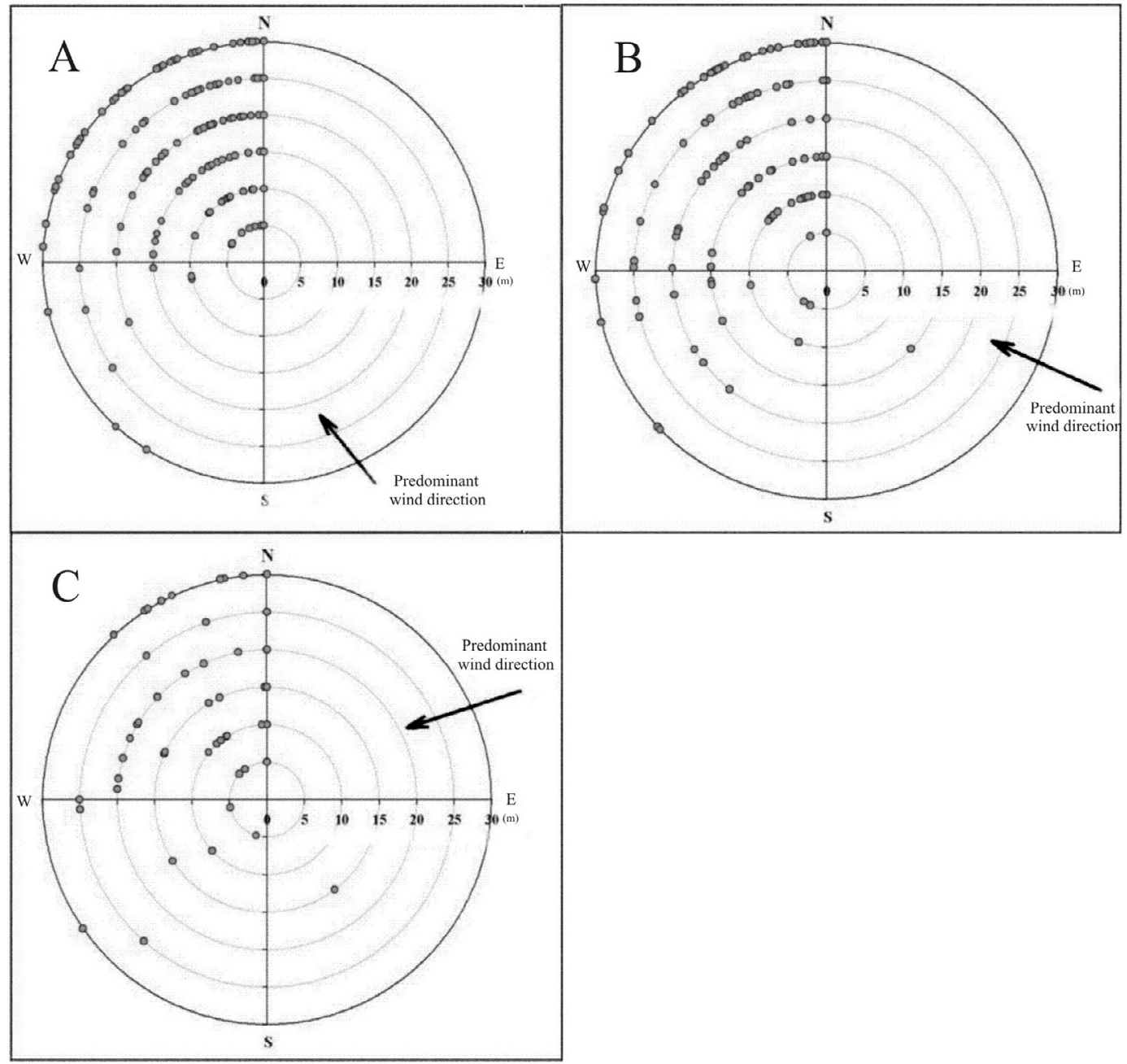

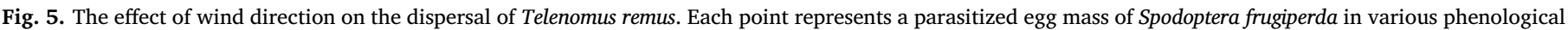
stages of soybean. A) V7, B) R3 and C) R6. 2012/13 season. Londrina, PR, Brazil.

\section{Discussion}

The objective of our research was to evaluate the dispersal capacity of released T. remus adults and the spatial pattern of parasitism, using $S$. frugiperda eggs as traps in maize and soybean crops during different phenological development stages and climatic conditions. The study is important because augmentative biological control (ABC) programs use mass release of egg parasitoids such as T. remus for a fast effect of the natural enemy rather than its establishment over a longer period (Corbett and Rosenheim, 1996). To achieve this, insects must spread rapidly from release points throughout the infested area (Zappala et al., 2012). It must also be considered that a high dispersal tendency of a parasitoid could lead to ineffective control (Hougardy and Mills, 2006) because a higher investment in dispersal could limit the time a species spends controlling the pest in the target crop. Not only can an extremely high dispersal rate lead to a low effective population size at the release point but also to low densities at the leading edge of the invading front of the biological control agent. On the other hand, extremely low dispersal rates can result in local extinction or low fitness through inbreeding and insufficient spread at the time of establishment (Heimpel and Asplen, 2011). Therefore, knowledge of the dispersal capacity of $T$. remus is of great theoretical and practical interest for the improvement of $\mathrm{ABC}$ strategies (Caltagirone, 2001). Despite this importance, there are only a few studies concerning the dispersal behavior of biological control agents in the field, mainly because of the difficulties of measuring the dispersal ability of small insects (Godfray, 1994; Hougardy and Mills, 2006; Tabone et al., 2010).

Overall, our results indicate that $T$. remus reared on either $S$. frugiperda eggs or on $C$. cephalonica eggs was able to disperse at different development stages of both studied crops (soybean and maize) and to locate the target pest ( $S$. frugiperda eggs). Mean dispersal distance (MD) of $T$. remus varied from a minimum of $14.49 \mathrm{~m}$ to a maximum of $22.34 \mathrm{~m}$ under different trial conditions. These values are higher than those observed for Trichogramma spp., another Lepidoptera egg parasitoid. Trichogramma pretiosum MD on soybeans was only $8.01 \mathrm{~m}$ according to Bueno et al. (2012). On the other hand, T. remus dispersal rates reported in our study were lower than those of Trichopria drosophilae Perkins (Hymenoptera: Diapriidae) released to control the invasive spotted wing Drosophila. In open field trials, T. drosophilae attacked Drosophila suzuki Matsumura (Diptera: Drosophilidae) in traps up to $40 \mathrm{~m}$ away from the release point (Rossi Stacconi et al., 2018). These findings suggest an intermediate dispersal rate for T. remus, which - according to the 'Goldilocks hypothesis' - is likely to maximize probability of establishment and appropriate dispersal range for a biological control agent released in the context of either importation or ABC (Heimpel and Asplen, 2011) and thus verifies the strong potential of T. remus as a successful biological control agent of Spodoptera spp.

It is important to note that the dispersal patterns of $T$. remus were highly influenced by wind and vegetation structure, explaining the relationship between parasitoid dispersal and wind direction, as well as the differing dispersal patterns of parasitoids released in maize and soybean crops. Wind has already been reported in the literature as an 


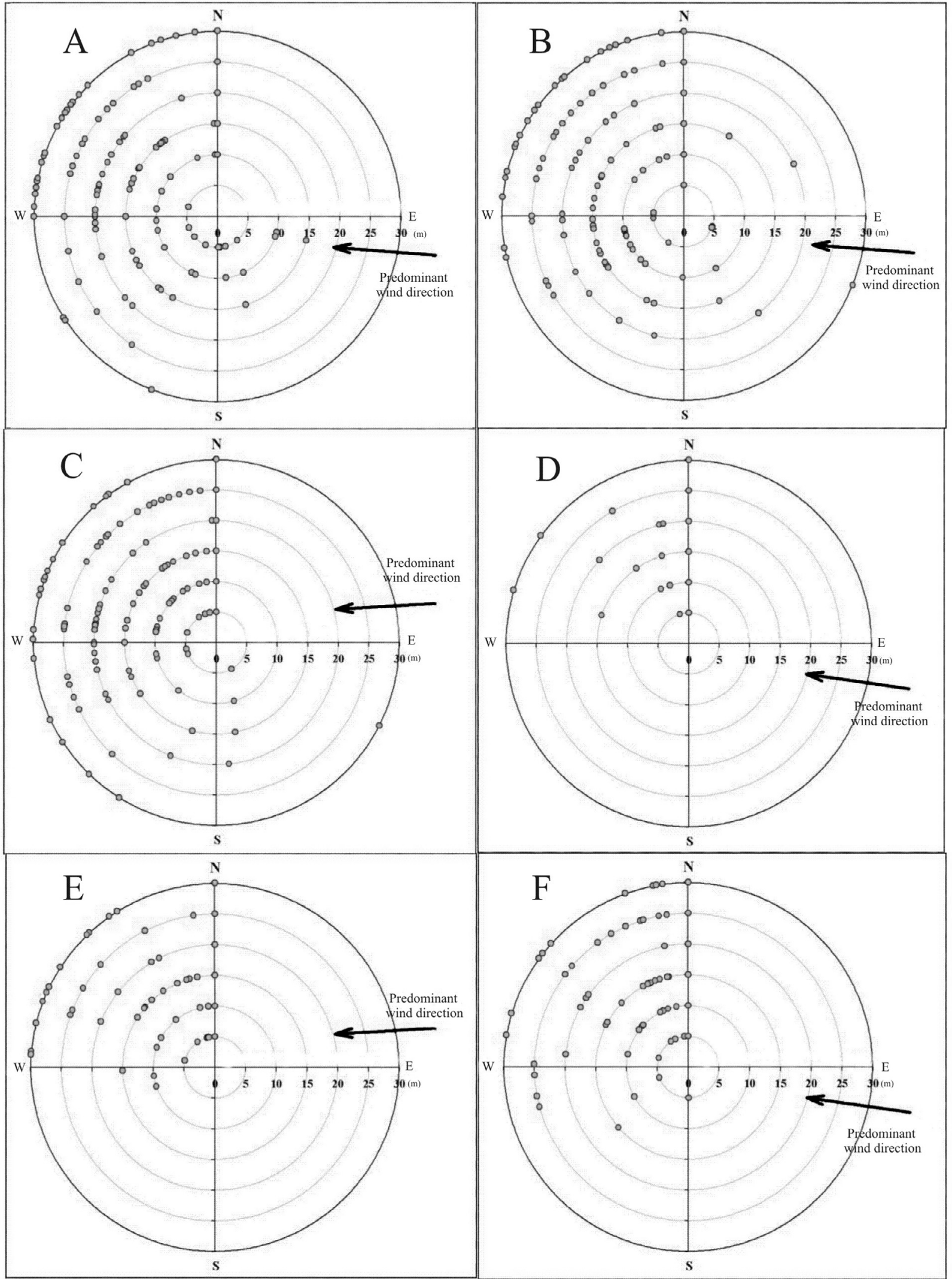

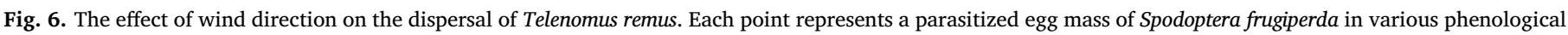

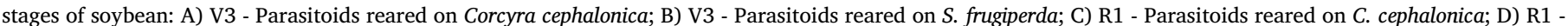

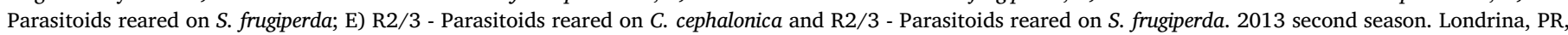
Brazil. 
Table 2

Mean distance (MD) and dispersal area $\left(\mathrm{s}^{2}\right)$ of Telenomus remus released in maize and soybean crops recorded in different trials and crop seasons.

\begin{tabular}{|c|c|c|c|c|c|c|}
\hline & \multirow[t]{2}{*}{ Crop/Season } & \multirow[t]{2}{*}{ Trial } & \multirow[t]{2}{*}{ Plant phenological state } & \multirow[t]{2}{*}{ Variables } & \multicolumn{2}{|l|}{ Parasitoid host colony } \\
\hline & & & & & Corcyra cephalonica & Spodoptera frugiperda \\
\hline \multirow[t]{18}{*}{ Maize } & \multirow[t]{6}{*}{2012 second season $^{1}$} & \multirow[t]{2}{*}{1} & \multirow[t]{2}{*}{$\mathrm{V} 2 / 3$} & $\mathrm{~s}^{2}\left(\mathrm{~m}^{2}\right)$ & - & $389.95 \pm 43.78$ \\
\hline & & & & $\mathrm{MD}(\mathrm{m})$ & - & $17.86 \pm 1.00$ \\
\hline & & \multirow[t]{2}{*}{2} & \multirow[t]{2}{*}{$\mathrm{V} 5 / 6$} & $\mathrm{~s}^{2}\left(\mathrm{~m}^{2}\right)$ & - & $369.92 \pm 6.64$ \\
\hline & & & & $\mathrm{MD}(\mathrm{m})$ & - & $17.65 \pm 0.02$ \\
\hline & & \multirow[t]{2}{*}{3} & \multirow[t]{2}{*}{ V8/9 } & $\mathrm{s}^{2}\left(\mathrm{~m}^{2}\right)$ & - & $420.08 \pm 12.18$ \\
\hline & & & & $\mathrm{MD}(\mathrm{m})$ & - & $18.82 \pm 0.29$ \\
\hline & \multirow[t]{6}{*}{$2012-13$ season $^{1}$} & \multirow[t]{2}{*}{4} & \multirow[t]{2}{*}{ V3 } & $\mathrm{s}^{2}\left(\mathrm{~m}^{2}\right)$ & - & $462.80 \pm 13.41$ \\
\hline & & & & $\mathrm{MD}(\mathrm{m})$ & - & $20.31 \pm 0.75$ \\
\hline & & \multirow[t]{2}{*}{5} & \multirow[t]{2}{*}{ V6/7 } & $\mathrm{s}^{2}\left(\mathrm{~m}^{2}\right)$ & - & $354.83 \pm 20.30$ \\
\hline & & & & $\mathrm{MD}(\mathrm{m})$ & - & $17.47 \pm 0.54$ \\
\hline & & \multirow[t]{2}{*}{6} & \multirow[t]{2}{*}{$\mathrm{V} 9 / 10$} & $\mathrm{~s}^{2}\left(\mathrm{~m}^{2}\right)$ & - & $419.77 \pm 14.79$ \\
\hline & & & & $\mathrm{MD}(\mathrm{m})$ & - & $18.49 \pm 0.38$ \\
\hline & \multirow[t]{6}{*}{2013 second season ${ }^{2}$} & \multirow[t]{2}{*}{7} & \multirow[t]{2}{*}{$\mathrm{V} 2$} & $\mathrm{~s}^{2}\left(\mathrm{~m}^{2}\right)$ & $369.69 \pm 17.68 \mathrm{~A}$ & $396.85 \pm 22.91 \mathrm{~A}$ \\
\hline & & & & $\mathrm{MD}(\mathrm{m})$ & $17.08 \pm 0.79 \mathrm{~A}$ & $17.91 \pm 0.52 \mathrm{~A}$ \\
\hline & & \multirow[t]{2}{*}{8} & \multirow[t]{2}{*}{ V5 } & $\mathrm{s}^{2}\left(\mathrm{~m}^{2}\right)$ & $451.37 \pm 23.45 \mathrm{~A}$ & $397.38 \pm 22.94 \mathrm{~A}$ \\
\hline & & & & $\mathrm{MD}(\mathrm{m})$ & $19.05 \pm 0.88 \mathrm{~A}$ & $17.78 \pm 0.41 \mathrm{~A}$ \\
\hline & & \multirow[t]{2}{*}{9} & \multirow[t]{2}{*}{ V10 } & $\mathrm{s}^{2}\left(\mathrm{~m}^{2}\right)$ & $298.73 \pm 18.97 \mathrm{~B}$ & $408.61 \pm 23.59 \mathrm{~A}$ \\
\hline & & & & $\mathrm{MD}(\mathrm{m})$ & $15.56 \pm 0.99 \mathrm{~A}$ & $18.38 \pm 0.42 \mathrm{~A}$ \\
\hline \multirow[t]{12}{*}{ Soybean } & \multirow[t]{6}{*}{ 2012-13 season ${ }^{1}$} & \multirow[t]{2}{*}{10} & V7 & $\mathrm{s}^{2}\left(\mathrm{~m}^{2}\right)$ & - & $494.35 \pm 5.19$ \\
\hline & & & & $\mathrm{MD}(\mathrm{m})$ & - & $20.50 \pm 0.18$ \\
\hline & & 11 & R3 & $\mathrm{s}^{2}\left(\mathrm{~m}^{2}\right)$ & - & $456.56 \pm 29.15$ \\
\hline & & & & $\mathrm{MD}(\mathrm{m})$ & - & $19.62 \pm 0.45$ \\
\hline & & 12 & R6 & $\mathrm{s}^{2}\left(\mathrm{~m}^{2}\right)$ & - & $300.87 \pm 10.49$ \\
\hline & & & & $\mathrm{MD}(\mathrm{m})$ & - & $14.95 \pm 0.29$ \\
\hline & 2013 second season $^{2}$ & 13 & V3 & $\mathrm{s}^{2}\left(\mathrm{~m}^{2}\right)$ & $287.90 \pm 16.62 \mathrm{~A}$ & $298.37 \pm 25.83 \mathrm{~A}$ \\
\hline & & & & $\mathrm{MD}(\mathrm{m})$ & $14.49 \pm 0.58 \mathrm{~A}$ & $15.18 \pm 0.35 \mathrm{~A}$ \\
\hline & & 14 & $\mathrm{R} 1$ & $\mathrm{~s}^{2}\left(\mathrm{~m}^{2}\right)$ & $561.61 \pm 32.42 \mathrm{~A}$ & $393.34 \pm 34.06 \mathrm{~B}$ \\
\hline & & & & $\mathrm{MD}(\mathrm{m})$ & $22.34 \pm 0.90 \mathrm{~A}$ & $17.64 \pm 0.41 \mathrm{~B}$ \\
\hline & & 15 & $\mathrm{R} 2 / 3$ & $\mathrm{~s}^{2}\left(\mathrm{~m}^{2}\right)$ & $498.07 \pm 28.75 \mathrm{~A}$ & $358.36 \pm 31.04 \mathrm{~B}$ \\
\hline & & & & $\mathrm{MD}(\mathrm{m})$ & $20.21 \pm 0.82 \mathrm{~A}$ & $16.83 \pm 0.39 \mathrm{~B}$ \\
\hline
\end{tabular}

Means \pm Standard Error (SE) followed by the same letter within each line were not statistically different $(t$ test, $p \leq 0.05)$.

-no data available.

1 Trials carried out within a $2826-\mathrm{m}^{2}$ circle infested with Telenomus remus reared on Spodoptera frugiperda eggs for 216 to 240 generations.

2 Trials carried out within a 2826- $\mathrm{m}^{2}$ circle infested with Telenomus remus reared on Spodoptera frugiperda eggs for 216 to 240 generations or infested with Telenomus remus reared on Corcyra cephalonica eggs for nine generations.

important factor for minute parasitic Hymenoptera (Corbett and Rosenheim, 1996). Probably because of its small size, T. remus has little flight control in wind conditions and therefore a relationship between parasitoid distribution and wind direction was recorded in almost all trials. Our data indicate that the use of this parasitoid in $\mathrm{ABC}$ programs requires a release methodology that considers wind conditions and direction for each particular area. In this regard, a perimetric distribution of the released insects can be desirable.

In addition to wind, temperature and humidity can also influence parasitoid dispersal capacity (Cave, 2000). Paranhos et al. (2007) found correlations between the average dispersal distance (MD) of Diachasmimorpha longicaudata (Hymenoptera: Braconidae) in citrus orchards in Piracicaba-SP, Brazil, and climate variables in different seasons of the year. However, in our trials T. remus dispersal appeared unrelated to climate parameters (temperature and humidity) with the exception of trial 15 (on soybean, second season of 2013) where a mean temperature of $17.9^{\circ} \mathrm{C}$ was recorded (the lowest temperature of all trials). This deviation from temperature and humidity ranges of the other trials with a mean temperature between $19.6{ }^{\circ} \mathrm{C}$ and $26.7^{\circ} \mathrm{C}$ possibly explains the difference in $T$. remus dispersal. Females of this parasitoid are able to parasitize their hosts at temperatures between 15 and $31{ }^{\circ} \mathrm{C}$ with superior performance at or above $20^{\circ} \mathrm{C}$ and with a significantly higher percentage of emergence between 20 and $31{ }^{\circ} \mathrm{C}$ (Bueno et al., 2008). Similar results were reported by Pomari et al. (2012), where the optimum range for development of T. remus was between 22 and $28^{\circ} \mathrm{C}$. Relative humidity above $60 \%$ is favorable for the development of $T$. remus (Pomari-Fernandes et al., 2015). In all our trials (Table 1), temperature and humidity ranges most often represented favorable conditions for T. remus, and may explain why different weather conditions did not affect the results. Whether different observations would be made under weather conditions outside the ranges optimal for T. remus needs to be further studied in future experiments.

Only small differences in $T$. remus dispersal were observed between plant species and plant development stages of each species. The ranges of dispersal area and mean distance and parasitism rates calculated between trials were similar for both crops despite of differences in plant architecture, which can provide different degrees of shelter for pest eggs and, consequently, pose different obstacles to parasitism (Biever, 1972). In addition, canopy structure can influence the wind speed to which parasitoid individuals are exposed during the dispersal process (Fournier and Boivin, 2000). Nevertheless, it is possible that those difficulties caused by an increase of the search surface and by overall plant growth are compensated by a greater proximity between plants, facilitating the movement on leaf surfaces (walking), and reducing the flying distances between plants of the same row. This could be a possible explanation why we did not observe the expected decrease of $T$. remus dispersal in more developed crops. Although only small differences were found, it is important to note that parasitoid movement within a given environment can be influenced by plant architecture, height, spacing and phenological state (Maini and Burgio, 1990; Cloyd and Sadof, 2000; Gontijo et al., 2010). Jonsen et al. (2001, 2007) noted that Aphthona flea beetles dispersed faster when released to control leaf spurge in a grassy habitat than in a shrubby habitat. Thus, the nature of the vegetative habitat and its effect on the dispersal of natural enemies must be considered in order to determine how releases are performed (Zachrisson and Parra, 1998), and can differ from crop to crop as well as from biological control agent to biological control agent.

As indicated by regression analysis, dispersal decreased linearly 
with increasing distance of sampling points from the parasitoid release points. This suggests that a larger number of release points in $A B C$ are important, despite an increase in cost and high rates of inbreeding (Zappala et al., 2012).

\section{Conclusions}

Telenomus remus should be released at a minimum density of 35 points/hectare in soybean crops and 34 points/hectare in maize crops to ensure T. remus dispersal over $100 \%$ of the area in the worst case scenario.

Since wind direction influences the dispersal pattern of $T$. remus, the release methodology should be determined according to the wind conditions, possibly with preference for a perimetric distribution of the released insects.

\section{CRediT author statement}

Aline Pomari-Fernandes: Data curation; Investigation; Methodology; Project administration; Resources; Roles/Writing - original draft; Adeney de Freitas Bueno: Data curation; Formal analysis; Funding acquisition; Investigation; Methodology; Project administration; Resources; Supervision; Roles/Writing - original draft; Writing review \& editing; Sérgio Antonio De Bortoli: Funding acquisition; Investigation; Supervision; Roles/Writing - original draft; Writing review \& editing; Bruna Magda Favetti: Roles/Writing - original draft; Writing - review \& editing.

\section{Acknowledgements}

The authors thank Embrapa Soja, the 'Fundação de Amparo a Pesquisa de São Paulo (FAPESP, Brazil)', the Coordination for the Improvement of Higher Education Personnel, Brazil (CAPES) and the National Council for Scientific and Technological Development, Brazil (CNPq), grants 303779/2015-2 and 402797/2016-7, for their financial support and fellowships. Authors also thank Adair Vicente Carneiro, laboratory technician, for the help provided with the trials and drawing of the figures.

\section{References}

Beer, T., 2013. Beaufort wind scale. In: Bobrowsky, P.T. (Ed.), Encyclopedia of Natural Hazards. Encyclopedia of Earth Sciences Series. Springer, Dordrecht. https://doi.org/ 10.1007/978-1-4020-4399-4_24.

Biever, K.D., 1972. Effect of the temperature on rate of search by Trichogramma and its potential application in field releases. Environ. Entomol. 1, 194-197.

Bueno, R.C.O.D.F., Carneiro, T.R., Pratissoli, D., Bueno, A.D.F., Fernandes, O.A., 2008 Biology and thermal requirements of Telenomus remus reared on fall armyworm Spodoptera frugiperda eggs. Ciência Rural 38, 1-6.

Bueno, R.C.O.F., Parra, J.R.P., Bueno, A.F., 2012. Trichogramma pretiosum parasitism and dispersal capacity: a basis for developing biological control programs for soybean caterpillars. Bull. Biol. Control 102, 1-8.

Caltagirone, C., 2001. Landmark examples in classical biological control. Annu. Rev. Entomol. 26, 213-232.

Castillo, A., Infante, F., Valle, J., Espinoza, J.C., 2006. Dispersión del parasitoide africano Phymastichus coffea La Salle (Hymenoptera: Eulophidae) en un nuevo agroecosistema. Folia Entomol. 45, 319-327.

Cave, R.D., 2000. Biology, ecology and use in pest management of Telenomus remus. Biocontrol 21, 21-26.

Cloyd, R.A. Sadof, C.S., 2000. Effects of plant architecture on the attack rate of Leptomastix dactylopii (Hymenoptera: Encyrtidae), a parasitoid of the citrus mealy bug (Homoptera: Pseudococcidae). Environ. Entomol. 29, 535-541.

Corbett, A., Rosenheim, J.A., 1996. Quantifying movement of a minute parasitoid, Anagrus epos (Hymenoptera: Mymaridae), using fluorescent dust marking and recapture. Biol. Control 6, 35-44.

Dobzhansky, T., Wright, S., 1943. Genetics of natural populations x Dispersion rates in Drosophila pseudoobscura. Genetics 28, 304-340.

Fournier, F., Boivin, G., 2000. Comparative dispersal of Trichogramma evanescens and
Trichogramma pretiosum (Hymenoptera: Trichogrammatidae) in relation to environmental conditions. Environ. Entomol. 12, 55-63.

Godfray, H.C.J., 1994. Parasitoids: Behavioral and Evolutionary Ecology. Princeton University Press, Princeton, pp. 473.

Gontijo, L.M., Margolies, D.C., Nechols, J.R., Cloyd, R.A., 2010. Plant architecture, prey distribution and predator release strategy interact to affect foraging efficiency of the predatory mite Phytoseiulus persimilis (Acari: Phytoseiidae) on cucumber. Biol. Control 53, 136-141.

Greene, G.L., Leppla, N.C., Dickerson, W.A., 1976. Velvetbean caterpillar: a rearing procedure and artificial diet. J. Econ. Entomol. 69, 487-488.

Heimpel, G.E., Asplen, M.K., 2011. A "Goldilocks" hypothesis for dispersal of biological control agents. Biocontrol 56, 441-450.

Hougardy, E., Mills, N.J., 2006. The influence of host deprivation and egg expenditure on the rate of dispersal of a parasitoid following field release. Biol. Control 37, 206-213. Jonsen, I.D., Bourchier, R.S., Roland, J., 2001. The influence of matrix habitat on Aphthona flea beetle immigration to leafy spurge patches. Oecologia 127, 287-294.

Jonsen, I.D., Bourchier, R.S., Roland, J., 2007. Effect of matrix habitat on the spread of flea beetle introductions for biological control of leafy spurge. Landscape Ecol. 22, 883-896.

Lopes, J.R.S. Estudos bioetólogicos de Trichogramma galloi (Zucchi, 1988) (Hym. Trichogrammatidae) para controle de Diatraea saccharalis (Fabr., 1794) (Lep. Pyralidae). Piracicaba, 1988. 141p. Dissertação (Mestrado) - Escola Superior de Agricultura "Luiz de Queiroz", Universidade de São Paulo.

Maini, S., Burgio, G., 1990. Biological control of the European maize borer in protected pepper by Trichogramma maidis Pint. and Voeg. and Bacillus thruringiensis Berl. Trichogramma and Other Egg Parasitoids p. 213-216. Proceedings, ${ }^{\text {rd }}$ International Symposium, Les Colloques. Institut. National de La Recherche Agronomique (INRA), Paris, France, San Antonio, TX, USA 23-27 September 1990.

Paranhos, B.A.J., Mendes, P.C.D., Papadopoulos, N.T., Walder, J.M.M., 2007. Dispersion patterns of Diachasmimorpha longicaudata (Hymenoptera: Braconidae) in citrus orchards in southeast Brazil. Biocontrol Sci. Technol. 17, 375-385.

Parra, J.R.P., 1997. Trichogramma e o controle biológico aplicado. In: Parra, J.R.P., Zucchi, R.A. (Eds.), Técnicas de criação de Anagasta kuehniella, hospedeiro alternativo para produç̃o de Trichogramma. FEALQ, Piracicaba, pp. 324

Parra, J.R.P., 2001. Técnicas de criação de insetos para programas de controle biológico. Piracicaba, ESALQ/FEALQ, pp. 137.

Pedrasi, T.C. \& Parra, J.R.P., 1986. Técnica de criação e determinação das exigências térmicas de Telenomus remus Nixon (Hymenoptera: Scelionidae). In: Congresso Brasileiro De Entomologia, 10., 1986, Rio de Janeiro. Resumos... Rio de Janeiro: SEB, pp. 227.

Perkins, W.D., 1979. Laboratory rearing of the fall armyworm. Fla. Entomol. 62, 87-91.

Pomari, A.F., Bueno, A.F., Bueno, R.C.O.F., Menezes Junior, A.O., 2012. Biological characteristics and thermal requirements of the biological control agent Telenomus remus (Hymenoptera: Platygastridae) reared on eggs of different species of the genus Spodoptera (Lepidoptera: Noctuidae). Ann. Entomol. Soc. Am. 105, 72-81.

Pomari, A.F., Bueno, A.F., Bueno, R.C.O.F., Menezes Junior, A.O., Fonseca, A.C.P.F., 2013. Releasing number of Telenomus remus (Nixon) (Hymenoptera: Platygastridae) against Spodoptera frugiperda Smith (Lepidoptera: Noctuidae) in corn, cotton and soybean. Ciência Rural 43, 377-382.

Pomari-Fernandes, A., Queiroz, A.P., Bueno, A.F., Sanzovo, A.W., De Bortoli, S.A., 2015 The Importance of Relative Humidity for Telenomus remus (Hymenoptera: Platygastridae) Parasitism and Development on Corcyra cephalonica (Lepidoptera: Pyralidae) and Spodoptera frugiperda (Lepidoptera: Noctuidae) Eggs. Ann. Entomol. Soc. Am. 108, 11-17.

Rossi Stacconi, M.V., Amiresmaeili, N., Biondi, A., Carli, C., Caruso, S., Dindo, M.L. Francati, S., Gottardello, A., Grassi, A., Lupi, D., Marchetti, E., Mazzeto, F., Mori, N., Pantezzi, T., Tavella, L., Garzia, G.T., Tonina, L., Vaccari, G., Anfora, G., Loriatti, C., 2018. Host location and dispersal ability of the cosmopolitan parasitoid Trichopria drosophilae released to control the invasive spotted wing Drosophila. Biol. Control $117,188-196$

Sá, L.A.N., Parra, J.R.P., Silveira Neto, S., 1993. Capacidade de dispersão de Trichogramma pretiosum Riley, 1879 para controle de Anticarsia gemmatalis Hübner, 1818 em milho. Sci. Agricola 50, 226-231.

SAS Institute, 2009. SAS User's Guide: Statistics: Version 8.2, 6 ed. Cary.

Silveira Neto, S., Nakano, O., Barbin, D. \& Nova, N.A.V., 1976. Manual de ecologia dos insetos. Piracicaba, Ceres, pp. 419.

Stinner, R.E., Ridgway, R.L., Copedge, J.R., Morrison, R.K., Dickerson Junior, W.A., 1974 Parasitism of Heliothis eggs after field releases of Trichogramma pretiosum in cotton. Environ. Entomol. 3, 497-500.

Systat Software, 2010. Sigma Plot Statistics Users Guide. Systat Software.

Tabone, E., Bardon, C., Desneux, N., Wajnberg, E., 2010. Parasitism of different Trichogramma species and strains on Plutella xylostella L. on greenhouse cauliflower. J. Pest Sci. 83, 251-256.

Zachrisson, B., Parra, J.R.P., 1998. Dispersion capacity of Trichogramma pretiosum Riley, 1879 for the control of Anticarsia gemmatalis Hübner, 1818 in soybean. Sci. Agricola 55, 133-137.

Zappala, L., Campolo, O., Grande, S.B., Saraceno, F., Biondi, A., Siscaro, G., Palmeri, V., 2012. Dispersal of Aphytis melinus (Hymenoptera: Aphelinidae) after augmentative releases in citrus orchards. Eur. J. Entomol, 109, 561-568. 